\title{
PENGALAMAN IBU MENYUSUI SEBELUM, SAAT, DAN SETELAH ERUPSI MERAPI 2010
}

\author{
Erviana Dewi Muslikhah', Elsi Dwi Hapsari², Fitri Haryanti ${ }^{2}$ \\ ${ }^{1}$ Mahasiswa Program Studi Ilmu Keperawatan, Fakultas Kedokteran, \\ Universitas Gadjah Mada, Yogyakarta, 55281, Indonesia \\ ${ }^{2}$ Departemen Keperawatan Anak dan Maternitas, Fakultas Kedokteran, \\ Univesitas Gadjah Mada, Yogyakarta, 55281, Indonesia \\ E-mail: erviana.dewi.m@mail.ugm.ac.id
}

\begin{abstract}
ABSTRAK
Tujuan penelitian: Untuk mengetahui pengalaman ibu dalam memberikan ASI sebelum, saat, dan setelah terjadi bencana erupsi Merapi 2010. Metode: Penelitian dengan rancangan kualitatif dan pendekatan fenomenologi. Partisipan penelitian ialah 5 orang ibu menyusui yang berada di hunian tetap Cangkringan. Analisis data menggunakan metode Colaizzi. Pengumpulan data dilakukan pada bulan September sampai Desember 2013. Izin etik diperoleh dari Komisi Etik Fakultas Kedokteran Universitas Gadjah Mada. Hasil: Pada kondisi sebelum bencana, terdapat satu tema yang diperoleh yaitu pemberian ASI lancar meskipun ada kesulitan. Pada saat terjadi bencana, diperoleh dua tema yaitu kenyataan di shelter yang berbeda dengan harapan dan dukungan sosial diterima Ibu dari suami dan masyarakat. Pada kondisi setelah bencana diperoleh satu tema yaitu kelancaran Pemberian ASI. Kesimpulan: Pada kondisi bencana, ibu yang menyusui mengalami berbagai tantangan agar tetap dapat menyusui anaknya secara eksklusif. Ibu yang menyusui disarankan dapat mengantisipasi apabila sewaktu-waktu terjadi bencana untuk mempersiapkan bekal berupa pengetahuan terkait merawat payudara dengan benar serta menjaga agar ASI tetap lancar meskipun dalam kondisi cemas yaitu dengan tetap memberikan ASI pada anak dan mengkonsumsi makanan sehat agar nutrisi tercukupi. Bagi tenaga kesehatan diharapkan dapat lebih banyak memberikan edukasi terkait kesulitan dalam menyusui. Pemerintah diharapkan lebih memperhatikan kondisi kesehatan korban bencana khususnya kesehatan ibu dan anak.
\end{abstract}

Kata Kunci: ASI, bencana.

WOMEN'S EXPERIENCE OF BREASTFEEDING BEFORE, DURING AND AFTER THE 2010 ERUPTION OF MERAPI

ABSTRACT

Objective: To identify women's experience of breastfeeding before, during and after the 2010 eruption of Merapi. Methods: The study employed qualitative design and phenomenological approach. Participants consisted of 5 breastfeeding mothers in permanent housing of Cangkringan. Data were analyzed using Colaizzi. Data were collected from September to December 2013. Ethical clearance was obtained from the Ethics Committee of the Faculty of Medicine, Gadjah Mada University. Results: In the pre-disaster, one theme was obtained that breastfeeding was smooth despite of difficulties. During the disaster, two themes obtained that reality in shelters was different from their expectation and social support was received by mothers from their husbands and society. After the disaster, one theme was obtained that breastfeeding was smooth. Conclusion: During the disaster, breastfeeding mothers experienced various challenges in order to able to breastfeed their children exclusively. It is suggested that breastfeeding mothers could anticipate a disaster which might occur at any time by preparing knowledge of how to treat breast properly and to keep the breastmilk drain well despite of anxious conditions by breastfeeding continuously to children and consuming healthy food in order to obtain adequate nutrition. It is expected that healthcare workers provide further education related to difficulties in breastfeeding. It is expected that the government pays more attention to the health condition of disaster victims, particularly mother and child health. Keywords: Breastmilk, Disaster 


\section{LATAR BELAKANG}

Salah satu target yang ditetapkan pada Sustainable Development Goals (SDGs) terkait kematian anak adalah mengurangi kematian neonatal sekurang-kurangnya 12 per 1.000 kelahiran hidup dan kematian anak di bawah usia 5 tahun sekurang-kurangnya 25 per 1.000 kelahiran hidup pada tahun 2030 di semua negara (The United Nations Children's Fund/UNICEF, 2015). Pada tahun 2008 angka kematian bayi atau Infant Mortality Rate (IMR) di Indonesia yaitu 31,04/1.000 kelahiran hidup. Salah satu indikator untuk mencapai Indonesia sehat 2025 adalah menurunkan angka kematian bayi (AKB) dari 32,3/1000 kelahiran hidup pada tahun 2005 menjadi 15,5/1000 kelahiran hidup (Depkes RI, 2009).

Angka kematian bayi yang cukup tinggi di dunia dapat dihindari salah satunya dengan pemberian air susu ibu (ASI). Pemberian ASI semaksimal mungkin merupakan kegiatan yang berperan penting dalam pemeliharaan anak dan persiapan generasi penerus di masa depan. Menyusui merupakan pemberian terbaik pada kehidupan bayi. Hal ini dapat melindungi bayi dari penyakit diare, infeksi saluran pernafasan, dan meyediakan sumber nutrisi yang dibutuhkan bayi untuk tetap sehat dan tumbuh. Jika setiap anak diberikan ASI eksklusif selama enam bulan pertama hidupnya, setara dengan akan menyelamatkan sekitar 1,5 juta jiwa (UNICEF, 2007).

Bencana merupakan sebuah kondisi yang mengancam individu baik secara fisik maupun kejiwaan. Memberikan ASI pada saat kritis atau situasi bencana merupakan hal yang masih sulit untuk dilakukan. Dalam keadaan darurat, kebutuhan untuk menggunakan ASI pengganti, pasokan air bersih dan mandi, cuci, kakus (MCK) sulit untuk mendapatkan jaminan dan memiliki risiko yang tinggi bagi kesehatan (Young, dkk., 2004).

Penelitian di Indonesia dilakukan oleh Wardhani (2011) pada ibu korban erupsi Merapi untuk mengetahui status pemberian ASI, jenis makanan yang diberikan pada anak usia 0-2 tahun serta kondisi psikologis ibu. Hasil penelitian tersebut menunjukkan bahwa kondisi bencana memiliki pengaruh yang signifikan terhadap pemberian ASI eksklusif oleh ibu pada bayinya (Wardhani, 2011). Hal ini juga didukung dengan masih rendahnya pengetahuan ibu mengenai manfaat pemberian ASI dalam situasi bencana dan support system dari suami serta keluarga terdekat (Ahmad, 2011).

Tujuan penelitian ini ialah untuk mengetahui pengalaman ibu dalam memberikan ASI sebelum, saat, dan setelah terjadi bencana erupsi Merapi 2010.

\section{METODE}

Penelitian ini merupakan penelitian dengan rancangan kualitatif dan pendekatan fenomenologi. Sampel penelitian ialah ibu menyusui yang berada di hunian tetap Cangkringan. Partisipan dalam penelitian adalah 6 orang ibu. Analisis data menggunakan metode Colaizzi. Pengumpulan data dilakukan pada bulan September sampai Desember 2013. Izin etik diperoleh dari Komisi Etik Fakultas Kedokteran Universitas Gadjah Mada. 
HASIL

A. Karakteristik Partisipan

Tabel 1. Karakteristik data demografi partisipan di hunian tetap Cangkringan

\begin{tabular}{lcccccc}
\hline \multicolumn{1}{c}{ Karakteristik } & R1 & R2 & R3 & R4 & R5 & R6 \\
\hline Usia(tahun) & 33 & 28 & 38 & 41 & 41 & 38 \\
\hline $\begin{array}{l}\text { Pendidikan } \\
\text { Terakhir }\end{array}$ & SMA & SMP & SMA & SD & SMA & SMA \\
\hline Pekerjaan & IRT & IRT & IRT & IRT & IRT & IRT \\
\hline Status Paritas & P2A0 & P2A0 & P3A2 & P2A0 & P3A0 & P5A0 \\
\hline $\begin{array}{l}\text { Penghasilan (Rp/ } \\
\text { bln) }\end{array}$ & 400 ribu & \pm 800 ribu & \pm 2 juta & 600 ribu & \pm 1 juta & 1,5 juta
\end{tabular}
bln)

Riwayat Penyakit Asma

B. Karakteristik Anak

Tabel 2. Karakteristik kelahiran anak

\begin{tabular}{cccccc}
\hline $\begin{array}{c}\text { Anak dari } \\
\text { Partisipan }\end{array}$ & $\begin{array}{c}\text { Urutan } \\
\text { Anak ke... } \\
\text { dari... }\end{array}$ & $\begin{array}{c}\text { Jenis } \\
\text { Kelamin }\end{array}$ & Tanggal Lahir & $\begin{array}{c}\text { BB } \\
\text { Lahir } \\
\text { (gr) }\end{array}$ & $\begin{array}{c}\text { Waktu lahir } \\
\text { (Sebelum/Saat/ } \\
\text { Setelah Bencana) }\end{array}$ \\
\hline R1 & 2 dari 2 & Perempuan & 5 Maret 2010 & 2.700 & Sebelum bencana \\
\hline R2 & 2 dari 2 & Perempuan & $\begin{array}{c}\text { 8Agustus } \\
2010\end{array}$ & 3.500 & Sebelum bencana \\
\hline R3 & 3 dari 3 & Perempuan & $\begin{array}{c}\text { 28 Agustus } \\
\text { 2010 }\end{array}$ & 3.200 & Sebelum bencana \\
\hline R4 & 2 dari 2 & Perempuan & 2 Sept 2010 & 3.900 & $\begin{array}{c}\text { Sebelum } \\
\text { bencana }\end{array}$ \\
\hline R5 & 5 dari 5 & Perempuan & 25 Sept 2010 & 2.300 & Sebelum bencana \\
\hline
\end{tabular}

Sumber: Data primer.

Karakteristik partisipan pada penelitian ini ditampilkan pada Tabel 1. Tabel tersebut menunjukkan bahwa rentang usia partisipan adalah 28-41 tahun, empat dari enam partisipan mempunyai pendidikan akhir SMA, dan semuanya sebagai ibu rumah tangga. Berdasarkan karakteristik kelahiran anak (Tabel 2), semua anak partisipan yang diteliti untuk mengetahui pengalama ibu sebelum, selama, dan setelah bencana adalah berjenis kelamin perempuan dan bukan anak yang pertama. Anak partisipan sebelumnya digunakan untuk dapat mengetahui pengalaman lbu menyusui sebelumnya dan pengasuhan anak.

Penelitian ini menggali data tentang pengalaman ibu menyusui yang diklasifikasikan menjadi tiga waktu, yaitu sebelum, saat, dan setelah terjadi bencana erupsi Merapi 2010. Setelah dilakukan transkripsi wawancara dan membacanya secara berulang-ulang, peneliti memperoleh 
kata kunci dari setiap pernyataan partisipan. Kata kunci tersebut menjadi dasar terbentuknya subkategori dan akhirnya diperoleh kategori (tema).

Hasil penelitian ini menunjukkan pada kondisi sebelum bencana, terdapat satu tema yang diperoleh, yaitu pemberian ASI lancar meskipun ada kesulitan. Pada saat terjadi bencana, diperoleh dua tema, yaitu kenyataan di shelter yang berbeda dari harapan dan dukungan sosial diterima ibu dari suami dan masyarakat. Pada kondisi setelah bencana diperoleh satu tema, yaitu kelancaran pemberian ASI.
Berikut disajikan pengalaman ibu menyusui pada masing-masing waktu tersebut:

a. Sebelum bencana erupsi

Waktu sebelum bencana erupsi adalah ketika partisipan masih berada di rumah masing-masing dan belum terjadi erupsi. Pada waktu tersebut 4 dari 5 partisipan masih memiliki bayi yang berumur 1,5-2 bulan, sedangkan 1 partisipan memiliki bayi berusia 8 bulan.

Tema yang diperoleh dari waktu sebelum terjadi bencana erupsi dapat dilihat pada Tabel 3.

Tabel 3. Analisis data tema 1 sebelum bencana erupsi

\begin{tabular}{lcc}
\hline \multicolumn{1}{c}{ Kata Kunci } & Sub Kategori & Kategori /Tema \\
\hline - Pas di rumah & Keberadaan ibu & \\
- Di rumah & & \\
- Masih di rumah & Memberikan ASI pada & Pemberian ASI lancar meskipun ada \\
- Ngasih ASI & anak & \\
- Masih menyusui & & \\
- Nyusuin & & \\
- Agak kurang ASI-nya & Kesulitan menyusui \\
- Repot, anak kembar & & \\
- ASI berkurang & & \\
- Anak kelainan hormon & & \\
\hline
\end{tabular}

Sumber: data sekunder.

Berdasarkan skema tersebut didapatkan tema tentang kondisi sebelum terjadi erupsi yang terdiri atas 3 subtema: keberadaan ibu, memberikan ASI pada anak, serta kesulitan menyusui.

1. Keberadaan ibu

Pada waktu sebelum terjadi bencana erupsi, partisipan masih berada di rumahnya masing-masing. Partisipan masih melakukan aktivitas seperti biasanya. Berikut kutipan pernyataan partisipan.

"Saya menyusuinya waktu itu masih di rumah, Mbak."(R3)
"Itu saya masih di rumah, Mbak, terus tanggal 24 itu balita disuruh ngungsi sama lansia." (R4)

2. Memberikan ASI pada anak

Partisipan menyatakan bahwa pada waktu itu mereka memberikan ASI kepada anaknya. Empat dari lima partisipan menyusui anaknya yang saat itu masih berusia 1,5 bulan sampai 2 bulan, sedangkan partisipan 1 memberikan ASI eksklusif selama 6 bulan karena pada waktu itu usia anak sudah 8 bulan.

"Kalo anak kedua ASI eksklusif, Mbak,.." (R1). 


\section{Kesulitan menyusui}

Pada waktu memberikan ASI kepada anaknya, partisipan menemukan kesulitan untuk menyusui. Kesulitan ini berupa jumlah ASI yang berkurang karena setelah melahirkan ASI tidak langsung keluar. Meskipun tidak langsung keluar, partisipan tetap menyusui anaknya dan merasakan terkadang ASI tidak lancar. Berikut kutipan jawaban partisipan yang berkurang ASI-nya dengan riwayat operasi SC saat melahirkan anaknya:

“...awal-awal kan kalo kesulitan dalam memberikan ASI saya dulu operasi sesar, Mbak. Jadi, untuk pertama di rumah sakit itu saya agak kurang ASI-nya. Terus berkat dorongan temen-temen dan keluarga juga akhirnya saya makan itu apa namanya kayak sayuran...ehm...daun katuk. Ya, daun katuk itu kan bisa mbuat ASI-nya deres kan mbak. Nah setelah itu, alhamdulillah ASI saya bisa keluar lumayan banyak." (R3)

Sementara itu, partisipan 5 (R5) merasakan kesulitan dalam menyusui disebabkan anak R5 tersebut kembar. Partisipan menyatakan repot untuk menyusui pada dua anak sekaligus. Berikut kutipan pernyataan partisipan:
"Kan saya menyusui dua anak ya, Mbak. Kan kembar itu. Jadi ya repot, Mbak, harus ada yang bantu bawain anak yang satunya." (R5)

Selain menyatakan kesulitan menyusui dengan anak kembar, partisipan mengatakan bahwa salah satu dari anak yang kembar tersebut memiliki kelainan hormon. Hal tersebut membuat ibu menjadi tidak tenang dan merasa saat menyusui ASI nya menjadi berkurang.

"Ya kadang berkurang wong pikiran, Mbak. Ya, keadaannya seperti itu, Mbak. Dan anak saya ini kan ada kelainan hormon ya, Mbak. Jadi, kata dokter kadar testosteronnya tinggi. Padahal kan perempuan dan setelah dicek di lab itu perempuan. Tapi harus minum obat mbak seumur hidup (responden menangis)." (R5)

b. Saat bencana erupsi

Bencana erupsi terjadi tanggal 26 Oktober 2010, yaitu saat partisipan sudah dievakuasi dan tinggal di tempat pengungsian (shelter). Dari 5 partisipan, hanya ada 1 partisipan yang tinggal di rumah saudara dan tidak menempati shelter seperti partisipan yang lain. Tema pada saat terjadi bencana disajikan dalam Tabel 4 dan 5 . 
Tabel 4. Analisis data kategori 1 saat terjadi bencana

\begin{tabular}{|c|c|c|}
\hline Kata Kunci & Sub Kategori & Kategori/Tema \\
\hline $\begin{array}{l}\text { - } \text { Stres, nafsu makan } \\
\text { berkurang } \\
\text { - Sedih, susah } \\
\text { - Cemas, bingung } \\
\text { - Takut } \\
\text { - Susah tidur }\end{array}$ & $\begin{array}{l}\text { Meningkatnya respons } \\
\text { psikologis ibu }\end{array}$ & \\
\hline $\begin{array}{l}\text { - Masuk angin } \\
\text { - Sakit panas, batuk, } \\
\text { pilek } \\
\text { - Sesak nafas } \\
\text { - Demam } \\
\text { - Diare } \\
\end{array}$ & $\begin{array}{c}\text { Kondisi kesehatan anak } \\
\text { yang terganggu }\end{array}$ & $\begin{array}{c}\text { Kenyataan di shelter yang berbeda } \\
\text { dengan harapan }\end{array}$ \\
\hline $\begin{array}{l}\text { - Kadang pakai susu } \\
\text { sambung } \\
\text { - Pernah mencoba } \\
\text { diberikan } \\
\text { - Mencoba satu kali }\end{array}$ & Pemberian susu formula & \\
\hline $\begin{array}{l}\text { - Puting lecet } \\
\text { - Asi berkurang } \\
\text { - Air susu sedikit }\end{array}$ & $\begin{array}{l}\text { Gangguan dalam } \\
\text { menyusui }\end{array}$ & \\
\hline
\end{tabular}

Tabel 5. Analisis data kategori 2 saat terjadi bencana

\begin{tabular}{|c|c|c|}
\hline Kata Kunci & Sub Kategori & Kategori/Tema \\
\hline $\begin{array}{ll}\text { - } & \text { Mendorong } \\
\text { - 'Nengnengi' } \\
\text { (menenangkan), } \\
\text { nggendong } \\
\text { - Nyuruh menyusui } \\
\text { - Ndukung ngasih asi }\end{array}$ & Dukungan suami & $\begin{array}{l}\text { Dukungan sosial diterima lbu dari } \\
\text { suami dan masyarakat }\end{array}$ \\
\hline $\begin{array}{l}\text { - Selimut } \\
\text { - Sabun, minyak } \\
\text { - Makanan } \\
\text { - Susu formula }\end{array}$ & $\begin{array}{c}\text { Bantuan yang diterima di } \\
\text { shelter }\end{array}$ & \\
\hline
\end{tabular}


Berdasarkan tabel di atas terdapat 2 tema yang ditemukan saat terjadi bencana erupsi. Adapun penjelasan dari masingmasing tema dijabarkan sebagai berikut:

1. Keadaan di shelter yang berbeda dari harapan

a. Meningkatnya respons psikologis Ibu

Pada saat bencana terjadi, partisipan menunjukkan respons yang maladaptif. Hal tersebut terlihat dari pernyataan partisipan berikut.

"Iya, saya gelisah dan cemas sekali. Bingung gitu, Mbak.” (R1)

"Yo pengalamane ki piye yo... sedih lah, Mbak. Soale kan susah tho. Saya bawa bayi kemana-mana saya repot juga." (R2)

"Kondisi saya saat erupsi ya baikbiak saja dalam arti saya juga cemas juga." (R3)

Selain respons tersebut, partisipan juga mengalami susah tidur pada saat di shelter. Berikut pernyataannya.

"Ya suka gelisah gitu, Mbak. Jadi kalo pas teringat itu susah tidur, Mbak." (R4)

b. Kondisi kesehatan anak yang terganggu

Kondisi di shelter yang penuh dengan orang mengakibatkan gangguan kesehatan pada anak karena anak masih lemah daya tahan tubuhnya. Berikut kutipan jawaban partisipan tentang kondisi kesehatan anaknya pada saat berada di shelter.
"Ya waktu erupsi itu sering sakit e, Sakitnya ya panas, pilek gitu, terus nafsu makannya gak ada itu Iho mba." (R1)

\section{c. Pemberian susu formula}

Partisipan menyatakan memberikan susu formula pada saat di shelter. Partisipan mengaku hanya memberikannya sekali dan ada yang hanya untuk mencoba memberikan karena tersedia susu formula di shelter. Pernyataan partisipan dikutip sebagai berikut.

"lya saya tetap berikan ASI. Meskipun kadang saya pakai susu sambung. Kan kalo kadang-kadang saya makan gak minat gitu jadi saya berikan susu sambung." (R1

"Soalnya pas di Maguwoharjo itu kan banyak susu bantuan. Saya coba ngasih susu formula satu kali tapi ternyata malah mencret mungkin itu nggak kuat mungkin ya. Trus gak tak kasih lagi. Cuma satu kali itu tak kasih susu formula." (R2)

\section{d. Gangguan dalam menyusui \\ Partisipan mengatakan bahwa pada} saat di shelter, mereka mengalami kesulitan untuk menyusui karena puting yang lecet.

"Ya ada kesulitan. Ya itu mlecetmlecet gitu. Saya periksakan gak sembuh-sembuh dan anaknya gak mau nyusu lagi. Itu aja." (R1)

Selain karena puting yang lecet, kesulitan lainnya ialah karena ASI yang keluar sedikit. Hal ini terjadi karena partisipan kurang mengonsumsi sayuran. 
"Ho'oh kan jarang makan sayur tho jadi gak banyak keluar ASI-nya." (R2)

e. Dukungan sosial yang diterima ibu

a. Dukungan suami

Keinginan partisipan untuk tetap menyusui saat berada di shelter didorong oleh suami mereka. Partisipan mengatakan bahwa suami melakukan perannya dengan baik saat di shelter. Ketika partisipan sedang repot, suamilah yang membantu untuk mengurus anaknya. Berikut kutipan dari pernyataan pertisipan.

"Ya kalo suami itu ikut ngurus anak. Jadi kalo anak saya nangis ya dia ikut nggendong, neng-nengi. Kalo kemaren saya nggak sama orang tua mbak. Jadi ya itu suami perhatian gitu ikut ngurus anak." (R1)

"Yo ming mendukung kalo bisa ki dikasih ASI terus." (R2) b. Bantuan yang diterima di shelter

Partisipan menuturkan bahwa mereka menerima bantuan saat berada di shelter. Jenis bantuan yang diterima antara lain berupa logistik seperti makanan (mie instan, sarden, biskuit), selimut, dan susu formula. Bantuan tersebut didapatkan dari dinas kesehatan, LSM, serta ada yang mendapatkan langsung dari saudaranya.

"Ya alhamdulillah dapat bantuan dari pemerintah, saudara yang di luar juga." (R1)

\section{c. Setelah bencana erupsi \\ Waktu setelah bencana erupsi} ialah ketika partisipan menempati hunian tetap (huntap). Perpindahan partisipan dari shelter dan akhirnya menempati huntap terjadi dalam kurun waktu cukup lama, yaitu rentang selama 8 bulan. Tema tentang keadaan di huntap pada waktu setelah erupsi dapat dilihat pada Tabel 6.

Tabel 6. Analisis data kategori setelah terjadi bencana

\begin{tabular}{|c|c|c|}
\hline Kata Kunci & Sub Kategori & Kategori/Tema \\
\hline $\begin{array}{l}\text { - } \text { Anak lebih tenang } \\
\text { - } \\
\text { bafsu makan } \\
\text { bertambah } \\
\text { Berat badan } \\
\text { bertambah } \\
\end{array}$ & Kondisi anak lebih baik & \\
\hline $\begin{array}{ll}- & \text { Masih menyusui } \\
\text { - } & \text { Tetap menyusui } \\
\text { - } & \text { Lanjut ASI sampai } 2 \\
& \text { tahun } \\
\end{array}$ & Pemberian ASI lancar & Kelancaran pemberian ASI \\
\hline $\begin{array}{ll}\text { - } & \text { Bubur } \\
\text { - } & \text { Tim } \\
\text { - } & \text { Nasi lunak } \\
\text { - } & \text { Serelac } \\
\text { - } & \text { Bubur } \\
\end{array}$ & $\begin{array}{l}\text { Pemberian Makanan } \\
\text { Tambahan (PMT) }\end{array}$ & \\
\hline
\end{tabular}


Berdasarkan tabel tersebut didapatkan tema keadaan di huntap dengan tiga sub kategori, yaitu: kondisi anak, pemberian ASI serta pemberian PMT. Berikut dijelaskan masing-masing sub kategorinya.

1. Kondisi anak

Setelah berada di huntap, partisipan menyatakan bahwa kondisi anaknya menunjukkan kondisi yang lebih baik. Hal ini terlihat dari nafsu makan anak yang meningkat dan psikis anak yang sudah lebih tenang.

"Kalo sekarang ya gak sering sakit lagi, Mbak, kan itu kan pikirannya dah tenang gitu." (R1)

"Anak saya makannya lebih mau banyak." (R4)

\section{Pemberian ASI}

Pada saat berada di huntap, usia anak partisipan sudah lebih dari 8 bulan. Partisipan mengatakan bahwa tetap memberikan ASI sampai usia 2 tahun.

"Jadi ketiga anak saya itu dapat ASI eksklusif semua mbak selama 6 bulan dan lanjut ASI sampai 2 tahun lebih malah." (R3) "setelah itu ya masih diberikan lah mba, anak saya masih dapat ASI sampai 2 tahun."(R4)

3. Pemberian Pemberian Makanan Tambahan (PMT)

Di samping tetap memberikan ASI, partisipan telah memulai melakukan PMT kepada anaknya. Berikut kutipan pernyataan partisipan yang memberikan PMT pada anaknya yang telah berumur lebih dari 6 bulan.

"Ya setelah 6 bulan itu saya kasih pisang, Mbak, Nestle gitu." (R4)

4. PemberianASI kepada anak sebelumnya yang menyusu di luar waktu bencana

Selain meneliti pengalaman menyusui ibu pada waktu sebelum, saat, dan setelah erupsi pada anak terakhir, peneliti menemukan kategori tambahan, yaitu mengenai pemberian ASI kepada anak sebelumnya yang menyusu di luar waktu bencana. Hasil analisis dapat dilihat pada Tabel 7.

Tabel 7. Analisis data terkait pemberian ASI kepada anak sebelumnya

\begin{tabular}{|c|c|c|}
\hline Kata Kunci & Sub Kategori & Kategori/Tema \\
\hline $\begin{array}{l}\text { - Cuma } 2 \text { bulan } \\
\text { - Empat bulan saja } \\
\text { - Empat bulan } \\
\text { - Empat bulan }\end{array}$ & $\begin{array}{l}\text { Durasi pemberian ASI } \\
\text { eksklusif }\end{array}$ & \multirow{2}{*}{$\begin{array}{c}\text { Pemberian ASI lebih singkat } \\
\text { dan melibatkan kerabat dalam } \\
\text { pengasuhan anak }\end{array}$} \\
\hline $\begin{array}{l}\text { - Sering ditinggal kerja } \\
\text { - Dimong simbahe } \\
\text { - Ditinggal kerja }\end{array}$ & $\begin{array}{c}\text { Pengasuhan anak oleh } \\
\text { nenek }\end{array}$ & \\
\hline
\end{tabular}

Pada Tabel 7 didapatkan hasil bahwa terdapat perbedaan pemberian ASI pada anak yang bukan korban erupsi. Perbedaan ini berdasarkan durasi pemberian ASI eksklusif dan pengasuhan anaknya.
Sebagian besar partisipan memberikan ASI eksklusif hanya 4 bulan. Selain itu, pada pengasuhan anak, partisipan pada anak sebelum anak yang disusui waktu bencana ini sering meninggalkan anak untuk diasuh 
orang lain. Dalam hal ini pengasuh adalah ibu partisipan. Berikut kutipan pernyataan partisipan:

"Kalo anak kedua ASI eksklusif. Kalo anak pertama dulu kan sama mbahnya karena saya sambi untuk nyari ekonomi mbak, tapi kalo anak yang kedua sama saya terus. Jadi saya kasih susu eksklusif terus. Kalo anak pertama ya sama mbahnya gitu, Mbak." (R1)

\section{PEMBAHASAN}

Berdasarkan hasil analisis didapatkan fakta bahwa pada waktu sebelum bencana erupsi, mayoritas pastisipan masih berada di rumah dan memberikan ASI pada anaknya. Pada saat menyusui ditemukan adanya kesulitan, yaitu ASI yang tidak langsung keluar setelah ibu melahirkan. Menurut Utomo (2010), ASI yang berbentuk kolostrum diproduksi pada trimester kedua kehamilan (minggu ke-16) dan terus diproduksi sampai hari " $\mathrm{H}$ " kelahiran. Pada sebagian ibu, terkadang kolostrum sudah keluar pada trimester ketiga, tetapi pada banyak ibu kolostrum baru keluar pada hari ke-2 atau ke-3 setelah kelahiran. Kedua hal ini normal karena pada 48-72 jam pascakelahiran, tubuh ibu mulai meningkatkan produksi ASI, sehingga ibu merasakan "sensasi ASI", ketika payudara mengencang dan mengeluarkan kolostrum.

Pada penelitian ini partisipan (R3) mengonsumsi daun katuk agar ASI-nya dapat keluar dalam jumlah yang banyak (deras). Hal ini sejalan dengan penelitian Sa'roni, dkk (2004) yang meneliti manfaat ekstrak daun katuk terhadap pengeluaran ASI pada ibu postpartum. Hasil penelitian tersebut menunjukkan bahwa daun katuk memiliki pengaruh yang signifikan terhadap produksi ASI. Daun katuk sudah diproduksi sebagai sediaan fitofarmaka yang berkhasiat untuk melancarkan ASI. Selain itu, daun katuk yang bernama Latin Sauropus androgynus L. Merr memiliki kadar klorofil tinggi yang di dalamnya terkandung antioksidan dalam jumlah besar dan sangat bermanfaat untuk mencegah radikal bebas (Samad, dkk., 2014). Hal ini sejalan dengan penelitian Zuhra, dkk (2008) bahwa flavonoid dari daun katuk memiliki kandungan antioksidan yang kuat.

Partisipan mengakui mengalami kesulitan untuk menyusui karena ASI yang berkurang. Kesulitan dalam menyusui tidak hanya ditemukan pada waktu sebelum erupsi, tetapi pada saat terjadi erupsi partisipan mengalami gangguan dalam menyusui seperti puting yang lecet dan jumlah ASI yang berkurang. Kondisi ini disebabkan pikiran partisipan yang saat itu tidak tenang melihat keadaan anaknya yang sakit kelainan hormon (R5). Hal ini sejalan dengan penelitian Siregar (2004) bahwa produksi ASI sangat dipengaruhi oleh faktor kejiwaan. Ibu yang selalu dalam keadaan gelisah, kurang percaya diri, rasa tertekan dan berbagai bentuk ketegangan emosional akan mengalami kegagalan dalam menyusui. Lebih lanjut, panduan pemberian ASI yang dikeluarkan oleh The United Nations International Children's Fund/UNICEF (2012) menginformasikan bahwa terhentinya ASI karena stres atau rasa takut hanyalah untuk sementara. Hal tersebut terbukti bahwa proses menyusui menghasilkan hormon yang dapat meredakan ketegangan, memberikan ketenangan, dan mempererat ikatan kasih sayang antara ibu dan bayi.

Kesulitan menyusui pada saat berada di sheltermembuatbeberapa partisipan memilih untuk memberikan susu formula kepada anaknya. Mayoritas partisipan memberikan susu formula hanya untuk mencoba dan diberikan selang-seling dengan pemberian ASI. Hal tersebut justru memberikan dampak 
yang tidak baik bagi kesehatan anak karena anak mengalami diare setelah diberikan susu formula. Sementara itu, partisipan R3 tetap memberikan ASI eksklusif kepada anaknya. Selama berada di shelter partisipan tidak memberikan susu formula karena telah mengetahui dampak dari pemberian susu formula pada anak yang dapat menyebabkan obesitas dan penyakit. Pernyataan tersebut sesuai dengan penelitian yang dilakukan di Purworejo bahwa ASI dapat menurunkan risiko obesitas pada anak bila diberikan sampai usia 12-24 bulan (IDAI, 2013).

Saat terjadi erupsi, partisipan mulai dievakuasi oleh petugas dan dibawa ke shelter. Proses evakuasi yang berjalan pun membuat partisipan harus lari ke sana kemari. Hal ini berdampak terhadap psikis partisipan yang merasa kebingungan, takut, stress, bahkan trauma. Saat berada di shelter, respons psikologis partisipan masih berlanjut sehingga membuat nafsu makan menurun dan susah tidur. Keadaan di shelter yang penuh dan sesak dengan para pengungsi yang lain membuat kesehatan anak menjadi terganggu. Partisipan menyebutkan bahwa anak mereka mengalami demam, batuk, pilek, serta sesak nafas. Jika dilihat dari tandatandanya, kemungkinan anak mengalami infeksi saluran pernafasan akut (ISPA). Partisipan R3 menceritakan bahwa keadaan di shelter sangat padat dan lembab. Data ini memperkuat penelitian Cahyaningrum (2012) bahwa faktor lingkungan yang memicu kejadian ISPA pada balita di wilayah kerja Puskesmas Cangkringan, DIY pasca erupsi Merapi 2010 antara lain kepadatan penghuni, jenis lantai, dinding rumah, intensitas cahaya, atap rumah, debu, saluran pembuangan air limbah, serta kelembapan.

Hal lain yang dikeluhkan partisipan saat berada di shelter ialah kurangnya asupan sayuran dan buah. Makanan yang diperoleh selama di shelter adalah makanan instan seperti mi, biskuit, dan sarden. Hal ini membuat partisipan beranggapan bahwa ASI-nya menjadi berkurang karena jarang mendapatkan sayuran. UNICEF (2012) merekomendasikan bahwa meskipun gizi ibu kurang, ASI masih tetap dapat diberikan pada anaknya.

Dukungan menjadi faktor penting ibu untuk menyusui. Berdasarkan hasil wawancara, semua partisipan mendapatkan dukungan emosional yang berasal dari suami dan keluarga yaitu dukungan agar tetap memberikan ASI. Hal ini sesuai dengan penelitian Arora, dkk (2000) yang menyebutkan bahwa salah satu faktor yang mendukung ibu menyusui adalah dukungan dari keluarga. Pada suatu keluarga, pengalaman ibu dalam menyusui sangat besar pengaruhnya. Keberhasilan pemberian ASI tidak terlepas dari dukungan keluarga, baik suami maupun anggota keluarga lain seperti orangtua, mertua, nenek, saudara, dan sebagainya (Binn, dkk., 2004). Ibu yang mendapatkan dukungan dari pasangannya memberikan ASI pada bayinya $83 \%$, dibandingkan dengan ibu yang tidak mendapatkan dukungan dari pasangannya hanya 21\% memberikan ASI (Sinclair, dkk., 2003).

Setelah berada di shelter, partisipan kemudian menempati huntap. Pada saat di huntap, anak partisipan rata-rata telah berumur 10 bulan ke atas. Partisipan menuturkan bahwa sampai pada saat di huntap mereka mulai memberikan PMT kepada anaknya. PMT yang diberikan berupa bubur, nasi tim, dan pisang yang dilumatkan. Pemberian makanan tambahan menurut World Health Organization/WHO (2004) dalam Complementary Feeding adalah memberi makanan lain selain ASI. Makanan lain ini disebut dengan makanan tambahan. 
Dari hasil penelitian juga terdapat informasi tambahan mengenai pemberian ASI pada anak partisipan sebelumnya yang bukan merupakan anak yang disusui waktu bencana. Terdapat perbedaan dalam memberikan ASI dan pengasuh anak.

Pada anak sebelumnya, partisipan menyusui lebih singkat dan melibatkan nenek dalam pengasuhan anak dikarenakan partisipan bekerja dan tidak dapat memberikan ASI secara efektif. Hal ini sejalan dengan penelitian Rejeki (2008) yang menyebutkan bahwa faktor bekerja pada ibu yang menyusui akan menyebabkan ketidakberhasilan dalam menyusui karena ibu meninggalkan rumah dalam waktu yang cukup lama sehingga tidak dapat menyusui bayinya.

\section{SIMPULAN}

Padakondisibencana, ibuyang menyusui mengalami berbagai tantangan agar tetap dapat menyusui anaknya secara eksklusif. Hasil penelitian ini menunjukkan bahwa pada kondisi sebelum bencana, terdapat satu tema yang diperoleh, yaitu pemberian ASI lancar meskipun ada kesulitan. Pada saat terjadi bencana, diperoleh dua tema, yaitu kenyataan di shelter yang berbeda dengan harapan dan dukungan sosial diterima ibu dari suami dan masyarakat. Pada kondisi setelah bencana diperoleh satu tema, yaitu kelancaran pemberian ASI.

Hasil penelitian ini menyarankan agar para ibu yang menyusui dapat mengantisipasi apabila sewaktu-waktu terjadi bencana untuk mempersiapkan bekal berupa pengetahuan terkait merawat payudara dengan benar serta menjaga agar ASI tetap lancar meskipun dalam kondisi cemas. Hendaknya mereka tetap memberikan ASI kepada anak dan mengonsumsi makanan sehat agar nutrisi tercukupi.
Tenaga kesehatan yang berada dalam instansi maupun masyarakat diharapkan dapat lebih banyak memberikan edukasi tentang menyusu eksklusif, teknik menyusui, pijat oksitosin, perawatan payudara, dan mengurangi kecemasan serta memberikan solusi untuk mengatasi kesulitan tersebut. Mereka perlu memberikan edukasi terkait kesulitan dalam menyusui seperti puting lecet, ASI berkurang, dan mengurangi kecemasan serta memberikan solusi untuk mengatasi kesulitan tersebut. Bagi pemerintah, diharapkan mereka lebih memperhatikan kondisi kesehatan korban bencana khususnya kesehatan ibu dan anak.

\section{DAFTAR PUSTAKA}

Ahmad, A. 2011. "Menyusui merupakan Respon Penting dalam Kondisi Darurat/ Bencana". [Serial Online. Available from: http://pmi.rejanglebongkab.go.id/ menyusui-merupakan-respon-pentingdalam-kondisi-daruratbencana/. Diakses tanggal 30 Mei 2012.

Arora, S., Junkin, C.M., Wherer, J. and Kuhn, P. 2000. "Mayor Factor Influencing Breastfeeding Rates: Mother's Perception of Father's attitude and Milk Supply". Pediatrics. 106(5):67.

Binn C., Gilchrist D., Gracey, M., Zhang, M., Scoot, J., and Lee, A. 2004. "Factor Associated with Initiation of Breastfeeding by Aboriginal Mothers in Perth". Public Health Nutrition. 7(7): 857-861.

Cahyaningrum, P.F. 2012. "Hubungan Kondisi Faktor Lingkungan dan Angka Kejadian Infeksi Saluran Pernapasan Akut (Ispa) pada Balita di Wilayah Kerja Puskesmas Cangkringan Kabupaten Sleman Daerah Istimewa Yogyakarta". Skripsi. Universitas Negeri Yogyakarta.

Depkes RI. 2009. http://www.depkes.go.id/. Jakarta: Depkes RI. 
IDAI. 2013. "ASI dan Perannya dalam Mencegah Obesitas". Available from: http://idai.or.id/public-articles/klinik/ asi/air-susu-ibu-dan-perannya-dalampencegahan-obesitas.html. Diakses tanggal 11 Juli 2014.

Rejeki, S. 2008. "Studi Fenomenologi: Pengalaman Menyusui Eksklusif Ibu Bekerja di Wilayah Kendal Jawa Tengah". Media Ners, Volume 2, No 1, hal. 1-44.

Samad, A.P., Santoso, U., Lee, M., Nana, F. 2014. "Effects of Dietary Katuk (Sauropus androgynus L. Merr.) on Growth, Non-Specific Immune and Diseases Resistance Against Vibrio alginolyticus Infection in Grouper Epinephelus coioides". Available from: www.sciencedirect.com. Diakses tanggal 20 Juli 2014.

Sa'roni, Sadjimin,T., Sja'bani,M., \& Zulaela. 2004. Effectiveness of the Sauropus Androgynus (L.)Merr Leaf Extract in Increasing Mother's Breast Milk Production. Media Litbang Kesehatan, Vol. XIV, No.3.

Sinclair, S., Houston, V., Shields, J. \& Snelling, S. 2003. Breastfeeding Practices in Northern Ontario: a report from the northern ontario perinatal and child health survey consortium. Public Health Research Education and Development (PHRED) Program: 1-117.

Siregar, A. 2004. Pemberian ASI eksklusif dan faktor-faktor yang mempengaruhi. Medan: FKM US.

UNICEF. 2007. "At A Glance: IndonesiaBreastfeeding Saves Lives After Earthquake Disaster [Serial Online]".
Available from: URL: http://www.unicef. org/infobycountry/indonesia_35137. html?q=printme.Pdf. Diakses tanggal 27 Juli 2012.

UNICEF. 2012. "Pesan Hidup Sehat Dalam Kedaruratan". Available from: http://www.unicef.org/indonesia/id/ PHSDalamKedaruratan.pdf. Diakses tanggal 9 Juli 2014.

UNICEF. 2015. "Child Survival". Available from: http://data.unicef.org/topic/childsurvival/child-survival-sdgs/. Diakses tanggal 27 Februari 2017.

Utomo, S.B. 2010. "Berapa Lama Bayi Bisa Bertahan Tanpa Makanan Minuman Apa pun Setelah Lahir". AIMI. Available from: http://www.wishingbaby.com/ berapa-lama-bayi-bisa-bertahan-tanpamakanan-minuman-apapun-setelahlahir/. Diakses tanggal 17 Juli 2014.

Young, H., Borrel, A., Holland, D., Salama, P. 2004. Public Nutrition In Complex Emergencies. Available from: www. thelancet.com Vol 365 November 20, 2004. Diakses tanggal 31 Juli 2012.

Wardhani, D. 2011. Pola Pemberian Asi oleh Ibu Korban Erupsi Merapi Di Kecamatan Cangkringan. Fakultas Kedokteran UGM. Yogyakarta.

WHO. 2004. Pemberian makanan tambahan (makanan untuk anak menyusui). Jakarta: EGC.

Zuhra, C.F., Tarigan, J.Br., dan Sihotang, H. 2008. "Aktivitas Antioksidan dan Senyawa Flavonoid dari Daun Katuk (Saurus Androgonus (L) Merr.)". Jurnal Biologi Sumatera, 3 (No.1) 7-10. 